DOI 10. 18307/2018. 0603

(c) 2018 by Journal of Lake Sciences

\title{
太湖西部环湖河道污染物输移速率变化特征”
}

\author{
朱金格 ${ }^{1}$, 刘 金金 $^{2}$,邓建才 ${ }^{1}$, 彭俊翔 $^{2}$, 张海涛 $^{2}$ \\ ( 1 : 中国科学院南京地理与湖泊研究所湖泊与环境国家重点实验室, 南京 210008) \\ (2:中国科学院大学,北京 100049)
}

\begin{abstract}
摘 要: 阐明污染物出人湖输移速率对于湖泊陆域污染控制具有重要意义. 本文研究了太湖西部主要环湖河道总氮 $(\mathrm{TN})$ 、溶解性总氮 $(\mathrm{DTN})$ 、总磷 $(\mathrm{TP}) 、$ 、溶解性总磷 $(\mathrm{DTP})$ 和高锰酸盐指数 $\left(\mathrm{COD}_{\mathrm{Mn}}\right)$ 输移速率变化特征. 结果表明环湖河 道上述指标净输人速率分别为 707.9、727.0、28.8、18.2 和 $700.9 \mathrm{~g} / \mathrm{s}$. 城东港、百渎港、大浦港和沙塘港 4 条河道 TN、DTN、 $\mathrm{TP} 、 \mathrm{DTP}$ 和 $\mathrm{COD}_{\mathrm{Mn}}$ 输人速率分别占西部河道总输人速率的 $62.7 \% 、 63.6 \% 、 67.1 \% 、 66.6 \%$ 和 $64.8 \%$. 太浦河、长览港和大钱 港 TN、DTN、TP、DTP 和 $\mathrm{COD}_{\mathrm{Mn}}$ 输出速率占总输出的 $86.5 \% 、 86.9 \% 、 85.0 \% 、 85.3 \%$ 和 $80.6 \%$. 污染物净输人速率受水情影 响, TN 和 DTN 浓度汛前最大, 而 TP、DTP、COD ${ }_{\mathrm{Mn}}$ 浓度汛期增大, 汛后分别降低 $44.2 \% 、 48.8 \%$ 和 $39.8 \%$. 城东港氮、磷输人 速率受浓度控制, 其他河道各指标输移速率受流量控制. 近岸湖体 TN 浓度与人湖速率呈显著正相关, 而离岸湖体 TN、 $\mathrm{TP} 、 \mathrm{COD}_{\mathrm{Mn}}$ 浓度对人湖速率的变化响应不明显.
\end{abstract}

关键词: 控氮; 人湖河道;外源污染; 太湖西部;输移速率

\section{Pollutant transport rates in the rivers around western Lake Taihu}

\author{
ZHU Jinge ${ }^{1}$, LIU Xin ${ }^{2}$, DENG Jiancai ${ }^{1}$, PENG Junxiang ${ }^{2}$ \& ZHANG Haitao ${ }^{2}$ \\ (1: State Key Laboratory of Lake Science and Environment, Nanjing Institute of Geography and Limnology, Chinese Academy \\ of Sciences, Nanjing 210008, P.R. China) \\ (2: University of Chinese Academy of Sciences, Beijing 100049, P.R.China)
}

\begin{abstract}
Elucidating transport rate of pollutants of the rivers around the lake is of great significance to clarify and control the external pollution. Spatial and temporal variations of pollutants transport rate of the rivers around western Lake Taihu were studied according to monthly investigation. The results show that the net input rate of total nitrogen( TN) to the lake was $707.9 \mathrm{~g} / \mathrm{s}$, slightly lower than that of dissolved total nitrogen (DTN, $727.0 \mathrm{~g} / \mathrm{s}$ ). The input rate of total phosphorus (TP), dissolved total phosphorus (DTP) and permanganate index $\left(\mathrm{COD}_{\mathrm{Mn}}\right)$ were $28.8 \mathrm{~g} / \mathrm{s}, 18.2 \mathrm{~g} / \mathrm{s}$ and $700.9 \mathrm{~g} / \mathrm{s}$, respectively. The input of pollutants was mainly form Chengdong River, and followed by Baidu River, Dapu River and Shatang River. The input rates of TN, DTN, TP, DTP and $\mathrm{COD}_{\mathrm{Mn}}$ in the 4 rivers accounted for $62.7 \%, 63.6 \%, 67.1 \%, 66.6 \%$ and $64.8 \%$ of the total input rate respectively. The output of the pollutants was mainly via Taipuhe River, Changdou River and Daqian River and accounted for 86.5\%, 86.9\%, $85.0 \%, 85.3 \%$ and $80.6 \%$ of the total output rate, respectively. The net input rate of TN and DTN was high before flood season, decreased about $25.0 \%$ in flood season. The net input rate of TP, DTP and $\mathrm{COD}_{\mathrm{Mn}}$ increased in flood season, whereas decreased about $44.2 \%$, 48.8\% and 39.8\% , respectively after flood season. The transport rate of nitrogen and phosphorus in Chengdong River was significantly influenced by its concentration, but transport rate of each index in other rivers was influenced by flow flux. The concentration of TN in nearshore lakes was not significantly correlated with TN concentration of rivers, but significant positive correlated with the transport rate of surrounding rivers. Concentrations of $\mathrm{TN}, \mathrm{TP}$ and $\mathrm{COD}_{\mathrm{Mn}}$ of offshore lakes have no obvious response to the changes of pollutants input rates.
\end{abstract}

Keywords: Nitrogen control; inflow rivers; external pollution; western Lake Taihu; transport rates

* 国家自然科学基金项目(51609235)、江苏省自然科学基金项目( BK20151063) 和国家水体污染控制与治理科技重 大专项 (2017ZX07205002) 联合资助. 2018-01-16 收稿; 2018-03-07 收修改稿. 朱金格(1983 ), 男, 博士, 助理 研究员; E-mail: jgzhu@ niglas.ac.cn. 
流域污染物外部输人是造成湖泊水质恶化及生态系统受到破坏的重要原因. 太湖地处长江三角洲平原 水网区, 周边河网密布, 出人湖河道 (溇港) 228 条, 其中口门敞开的河道有 62 条, 主要分布于太湖西部地区. 环湖河道污染物的大量输人增加了太湖污染负荷 ${ }^{[1-3]}$, 造成太湖西部湖区水质不能持续达标, 轻度富营养化 的态势难以转变. 在各项环保措施综合作用下,2007-2014 年环太湖主要河道氮、磷等污染物浓度呈降低趋 势 ${ }^{[4-5]}$, 但与太湖的控氮控磷目标相比, 人湖河道相对较高的污染物浓度持续对太湖水质改善和富营养化治 理形成了很大的压力. 围绕太湖环湖河道水质变化特征目前已有大量研究成果, 基本揭示了不同水文条件 下环湖河道水质的时空分布 ${ }^{[6-7]}$, 尤其是氮 ${ }^{[8-9]}$ 、磷 $^{[10]}$ 营养盐的变化特征. 对于湖泊水质管理而言, 人湖污染 物总量是需要重点考虑的因素, 弄清污染物输人量的时空变化, 对于进一步由太湖水质目标推算各河道或 控制单元的减排目标至关重要. 人湖污染总量除了与环湖河道水质密切相关, 还受人湖流量控制. 当前研究 一般基于流量与污染物浓度计算出月通量或年通量, 关注重点是总量的变化, 如滇池 ${ }^{[11]}$ 、巢湖 ${ }^{[12]}$ 和太 湖 ${ }^{[2-3,5]}$ 等重要湖泊的人湖污染物通量研究. 对于地处平原河网区的太湖流域, 河道水流方向多变, 出入湖通 量的估算依赖于高频次的水文水质同步观测. 本文基于太湖西岸主要环湖河道水文水质的同步观测, 从输 移速率的角度分析污染物出入湖速率的空间分布及不同水情下的变化, 探讨影响污染物输移速率的关键因 素, 及其与太湖近岸、离岸湖体水质的关系, 以期为太湖水质目标管理及流域水环境综合整治提供重要参数 与理论参考.

\section{1 材料与方法}

\section{1 研究区域}

选取太湖西部 21 条流量相对较大的河道为研究对象, 其中雅浦港往南至乌溪港之间的 12 条河道以及 太浦河位于江苏境内,合溪新港往东至汤溇港之间的 8 条河道位于浙江境内. 望虞河受 “引江济太”调度影 响较大且距离西部湖区相对较远, 本文未将其纳人研究范围. 为了探讨湖体污染物浓度对人湖河道的响应, 本文在近岸和离岸水体分别布点进行了水质的同步观测. 河道与湖体采样点空间分布见图 1.

\section{2 调查与样品分析}

2014 年 1 月 $14-15$ 日、 2 月 $25-26$ 日、 3 月 $26-27$ 日、 4 月 26 - 27 日、 5 月 $25-26$ 日、 6 月 $20-21$ 日、 7 月 $23-24$ 日、 8 月 $26-27$ 日、9 月 26-27日、10月 25-26日、 11 月 26- 27 日和 12 月 26- 27 日分别对 21 条河道进行了逐月流量观测和水样采集, 对湖体进行了同步水样采集. 流量采用 SonTek River Surveyor M9 走航式流速仪进行观测, 获取观测河道的断面形态、流量、平均流速信息. 在每个观测断面进行 4 次观测, 取 其流量平均值. 进行流量观测的同时, 利用采水器在河道中间位置进行水样采集, 采样深度为水面以下 20 $\mathrm{cm}$, 采集水样 $1 \mathrm{~L}$. 在湖体 $\mathrm{L} 1$ 和 $\mathrm{L} 2$ 采样点利用采水器采集水下 $50 \mathrm{~cm}$ 处水样 $1 \mathrm{~L}$. 上述水样当天带回至中国 科学院太湖湖泊生态系统研究站, 参照《湖泊富营养化调查规范》 ${ }^{[13]}$ 进行总氮 (TN)、溶解性总氮 (DTN)、总 磷 $(\mathrm{TP})$ 、溶解性总磷 (DTP) 和高锰酸盐指数 $\left(\mathrm{COD}_{\mathrm{Mn}}\right)$ 等水化指标的分析. 其中, 氮、磷浓度测定采用碱性过 硫酸钾紫外分光光度法, $\mathrm{COD}_{\mathrm{Mn}}$ 测定采用酸性高锰酸钾法.

\section{3 统计分析}

根据太湖西部河道出入湖流量空间分布, 将雅浦港往南至乌溪港之间的 12 条河道归类为人湖河道,合 溪新港往南至太浦河的 9 条河道归类为出湖河道.

污染物输移速率 $V_{\mathrm{TN}} 、 V_{\mathrm{DTN}} 、 V_{\mathrm{TP}} 、 V_{\mathrm{DTP}} 、 V_{\mathrm{COD}_{\mathrm{w}}}$ 代表每秒种 TN、DTN、TP、DTP 和 $\mathrm{COD}_{\mathrm{Mn}}$ 的输人输出质量 $(\mathrm{g} / \mathrm{s})$. 河道 $i$ 的 $\mathrm{TN}$ 输移速率 $V_{\mathrm{TN} i}=C_{\mathrm{TN} i} \cdot Q_{i}$, 其中 $C_{\mathrm{TN}}$ 为 $\mathrm{TN}$ 浓度 $(\mathrm{mg} / \mathrm{L}) ; Q_{i}$ 为流速仪观测的流量 $\left(\mathrm{m}^{3} / \mathrm{s}\right)$. 将 21 条河道的同期 $V_{\mathrm{TN}}$ 累加, 即得到当前月份 $\mathrm{TN}$ 总输移速率 $V_{\mathrm{TN}_{\mathrm{r}}}$, 对 12 个月的 $V_{\mathrm{TN}_{\mathrm{T}}}$ 求平均, 即得到年均输移速 率 $(\mathrm{g} / \mathrm{s})$. 用相同办法计算 DTN、TP、DTP 和 $\mathrm{COD}_{\mathrm{Mn}}$ 各条河道输移速率、总输移速率及年均输移速率.

利用 Pearson 相关性统计分析, 探讨各河道污染物浓度、输移速率与流量的相关性, 人湖河道污染物输 人速率与湖体污染物浓度的相关性. 利用 One-way ANOVA 进行 95\% 置信度水平下的单因素方差分析, 探讨 各河道在污染物浓度、输移速率方面的差异性. $P<0.05$ 代表具有显著性. 


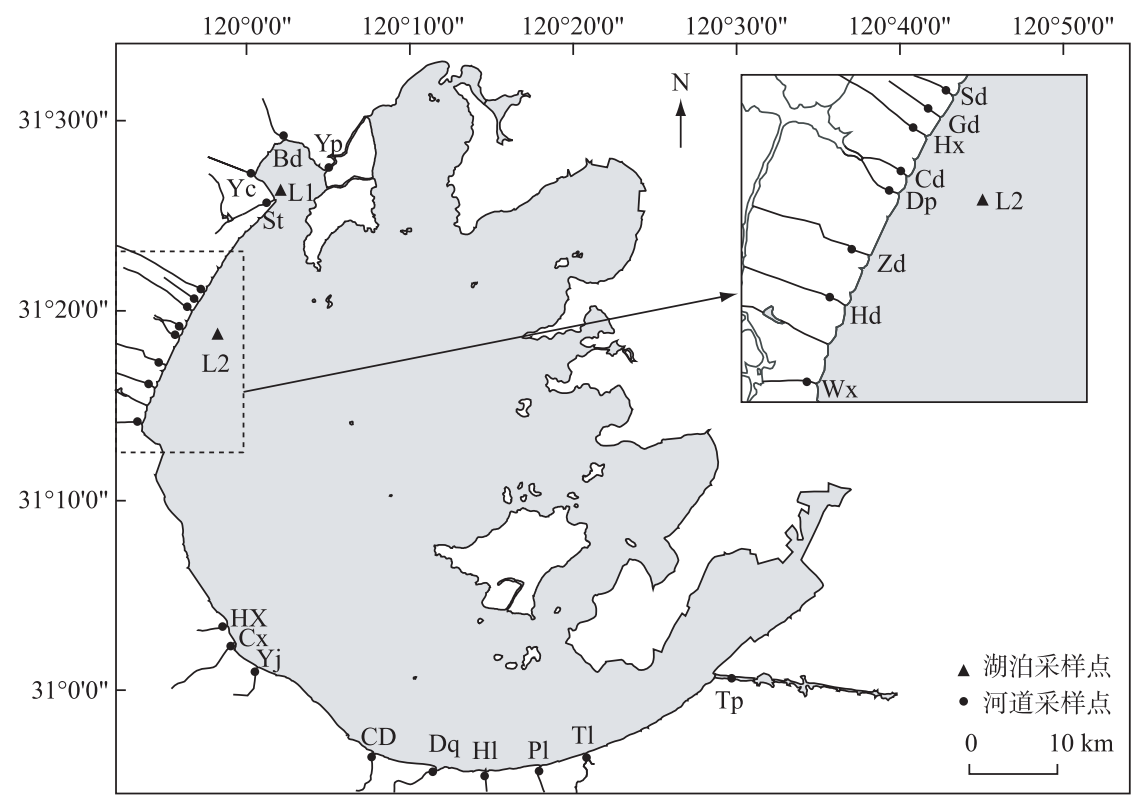

图 1 环太湖河道水文水质同步监测断面及湖体采样点 ( $\mathrm{Yp}$ 雅浦港, Bd 百渎港, $\mathrm{Yc}$ 殷村港, $\mathrm{St}$ 沙塘港, $\mathrm{Sd}$ 社渎港, $\mathrm{Gd}$ 官渎港, $\mathrm{Hx}$ 洪巷港, $\mathrm{Cd}$ 城东港, $\mathrm{Dp}$ 大浦港, $\mathrm{Zd}$ 朱渎港, $\mathrm{Hd}$ 黄渎港, $\mathrm{Wx}$ 乌溪港, $\mathrm{HX}$ 合溪新港,

$\mathrm{Cx}$ 长兴港, $\mathrm{Yj}$ 杨家浦港, $\mathrm{CD}$ 长兒港, $\mathrm{Dq}$ 大钱港, $\mathrm{Hl}$ 幻溇港, $\mathrm{Pl}$ 兴溇港, $\mathrm{Tl}$ 汤溇港, $\mathrm{Tp}$ 太浦河)

Fig. 1 Monitoring sections of the 21 rivers and water quality sampling sites of Lake Taihu

\section{2 结果与分析}

\section{1 环湖河道流量与水质}

太湖西部环湖河道流量具有较大的空间差异, 西北部河道总体为人湖河道, 年均最大人湖流量出现在 城东港 $\left(84.1 \mathrm{~m}^{3} / \mathrm{s}\right)$, 其次是百渎港 $\left(32.8 \mathrm{~m}^{3} / \mathrm{s}\right)$. 西南部河道以出湖为主, 年均最大出湖流量出现在太浦河 $\left(73.1 \mathrm{~m}^{3} / \mathrm{s}\right)$, 其次是长皃港 $\left(24.7 \mathrm{~m}^{3} / \mathrm{s}\right)$.

环湖河道年均 TN 浓度介于 $1.80 \sim 4.06 \mathrm{mg} / \mathrm{L}$ 之间(图 2), 空间上由北往南 TN 浓度逐渐降低. 人湖河道 和出湖河道 TN 平均浓度分别为 3.68 和 $2.45 \mathrm{mg} / \mathrm{L}$. 人湖河道 TN 浓度均值的年内变化与出湖河道具有显著 性差异 $(P=0.02)$. DTN 浓度介于 $1.30 \sim 3.85 \mathrm{mg} / \mathrm{L}$ 之间, 变化趋势与 TN 一致 $(r=0.909, P<0.01)$. DTN 在 $\mathrm{TN}$ 中的比例由北往南呈现出下降趋势, 人湖河道 DTN/TN 比为 $91.1 \%$, 出湖河道降至 $77.5 \%$, 表明湖体中 DTN 在 TN 中的占比小于人湖河道. TP 浓度介于 $0.082 \sim 0.209 \mathrm{mg} / \mathrm{L}$ 之间, 平均浓度为 $0.136 \mathrm{mg} / \mathrm{L}$. 人湖河 道和出湖河道 TP 平均浓度分别为 0.149 和 $0.118 \mathrm{mg} / \mathrm{L}$, 年内并不具显著性差异. $\mathrm{COD}_{\mathrm{Mn}}$ 浓度介于 $2.94 \sim 4.82$ $\mathrm{mg} / \mathrm{L}$ 之间, 平均浓度为 $4.04 \mathrm{mg} / \mathrm{L}$, 达到地表 III 类水标准. $\mathrm{TP}$ 和 $\mathrm{COD}_{\mathrm{Mn}}$ 由南往北的空间差异相对较小, 主要 原因在于人湖河道的浓度与西太湖浓度较为接近, 与 $\mathrm{TN}$ 浓度相比人湖污染负荷相对较小, 可见控氮依然是 河道外源治理的重点.

按照汛前 ( $1-4$ 月)、汛期 (5-9 月) 和汛后 (10-12 月) 分时段对各河道水质进行了统计. 汛前各河道 $\mathrm{TN}$ 浓度均高于汛期和汛后 (图 3), 其中人湖河道平均 TN 浓度汛前为 $4.65 \mathrm{mg} / \mathrm{L}$, 汛期平均浓度降低 $31.5 \%$, 为 $3.18 \mathrm{mg} / \mathrm{L}$, 汛后浓度略有上升, 为 $3.21 \mathrm{mg} / \mathrm{L}$, 与汛前浓度相比降低 $31.0 \%$. TP 浓度汛前、汛期和汛后人湖 浓度均值分别为 $0.13 、 0.19$ 和 $0.11 \mathrm{mg} / \mathrm{L}$, 汛期浓度升高 $46.2 \%$, 汛后浓度大幅下降. 空间上, 汛期各人湖河道 $\mathrm{TP}$ 浓度均高于汛前和汛后, 出湖河道无明显规律. $\mathrm{COD}_{\mathrm{Mn}}$ 汛前、汛期、汛后人湖浓度均值分别为 4.21、4.47 和 $3.60 \mathrm{mg} / \mathrm{L}$, 汛期浓度略有上升, 汛后浓度最低, 空间上, 人湖河道汛期浓度高. 环湖河道 $\mathrm{TN} 、 \mathrm{TP} 、 \mathrm{COD}_{\mathrm{Mn}}$ 浓度 在汛前和汛期和汛后都具有显著性差异 $(P<0.01)$. 总体而言, 汛期地表径流的汇人一定程度上稀释了人湖 


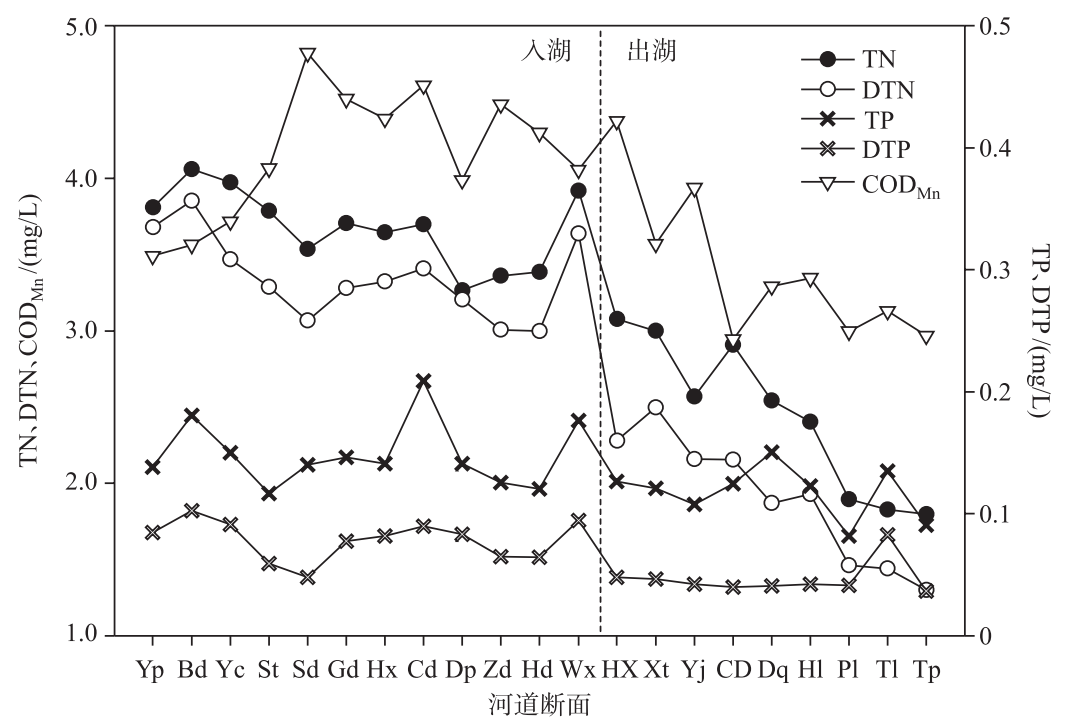

图 2 太湖西部环湖河道污染物浓度变化趋势

Fig. 2 Change trend of pollutant concentrations of the 21 rivers around western Lake Taihu

河道 $\mathrm{TN}$ 浓度,但 $\mathrm{TP}$ 和 $\mathrm{COD}_{\mathrm{Mn}}$ 浓度分别上升 $46.2 \%$ 和 $6.2 \%$, 汛后 $\mathrm{TN}$ 浓度回升, $\mathrm{TP}$ 和 $\mathrm{COD}_{\mathrm{Mn}}$ 浓度降低. 环湖 河道尤其是人湖河道污染物浓度的时空多变性加上流量的变化,增加了人湖污染物输移的复杂性.

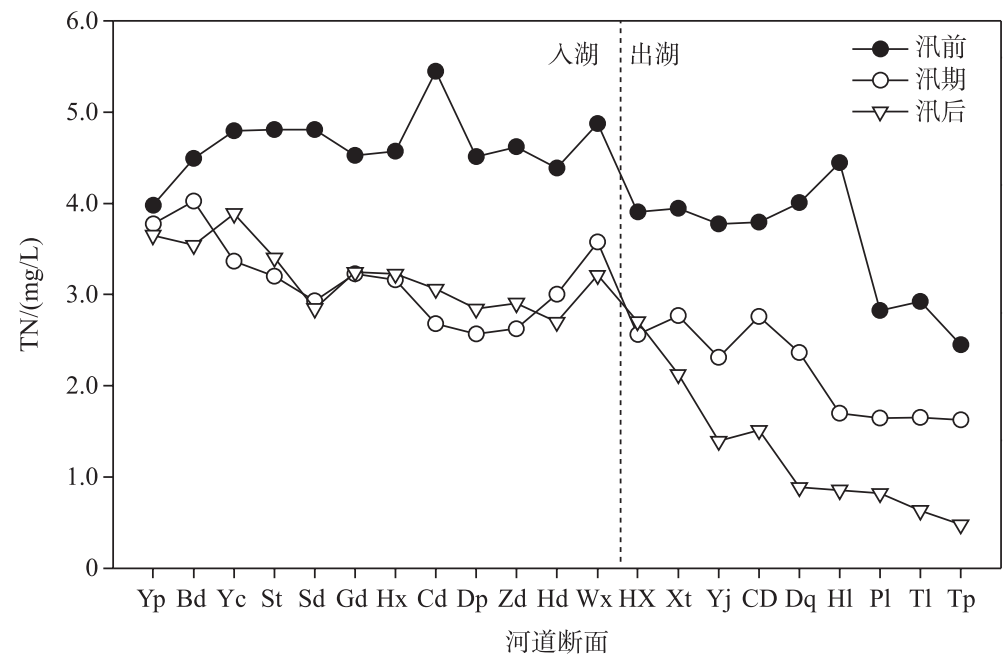

图 3 不同水情下太湖西部环湖河道 TN 浓度

Fig. 3 TN concentrations of the 21 rivers around western Lake Taihu in different hydrological conditions

\section{2 环湖河道污染物输移速率}

统计了各河道 $V_{\mathrm{TN}} 、 V_{\mathrm{DTN}} 、 V_{\mathrm{TP}} 、 V_{\mathrm{DTP}}$ 和 $V_{\mathrm{COD}_{\mathrm{Du}}}$ 月变化 (图 4), 发现 $\mathrm{TN}$ 最大输人速率可达 $646.5 \mathrm{~g} / \mathrm{s}$, 以城东港 为主要输人河道, 其平均输人速率为 $300.4 \mathrm{~g} / \mathrm{s}$; 最大输出速率为 $588.5 \mathrm{~g} / \mathrm{s}$, 以太浦河和长樂港输出为主, 平 均输出速率分别为 98.3 和 $93.3 \mathrm{~g} / \mathrm{s}$; 环湖河道 TN 总输人速率为 $963.6 \mathrm{~g} / \mathrm{s}$, 净输人速率为 $707.9 \mathrm{~g} / \mathrm{s}$. 各河道 DTN 输移速率与 TN 浓度均呈显著相关 $(P<0.05)$, 二者在各河道的分配及时间上的变化具有高度一致性. 需要注意的是, 出湖 DTN 比例下降造成 DTN 净输人速率为 $727.0 \mathrm{~g} / \mathrm{s}$, 略高于 TN 净输人速率. TP 最大输人 
速率为 $43.9 \mathrm{~g} / \mathrm{s}$, 同样以城东港为主要输人河道, 环湖河道 $\mathrm{TP}$ 总输人速率为 $43.9 \mathrm{~g} / \mathrm{s}$, 净输人速率为 $28.8 \mathrm{~g} / \mathrm{s}$. DTP 和 TP 输移速率的时空变化同样具有高度一致性 $(r=0.883, P<0.05)$, DTP 总输人速率为 $23.1 \mathrm{~g} / \mathrm{s}$, 净输 人速率为 $18.2 \mathrm{~g} / \mathrm{s}$. $\mathrm{COD}_{\mathrm{Mn}}$ 以城东港为主要输人河道, 其平均输人速率为 $392.6 \mathrm{~g} / \mathrm{s}$; 以太浦河输出为主, 平均 输移速率为 $179.8 \mathrm{~g} / \mathrm{s}$; 环湖河道 $\mathrm{COD}_{\mathrm{Mn}}$ 总输人速率为 $1093.9 \mathrm{~g} / \mathrm{s}$, 净输人速率为 $700.9 \mathrm{~g} / \mathrm{s}$, 与 $\mathrm{TN}$ 较为接近.
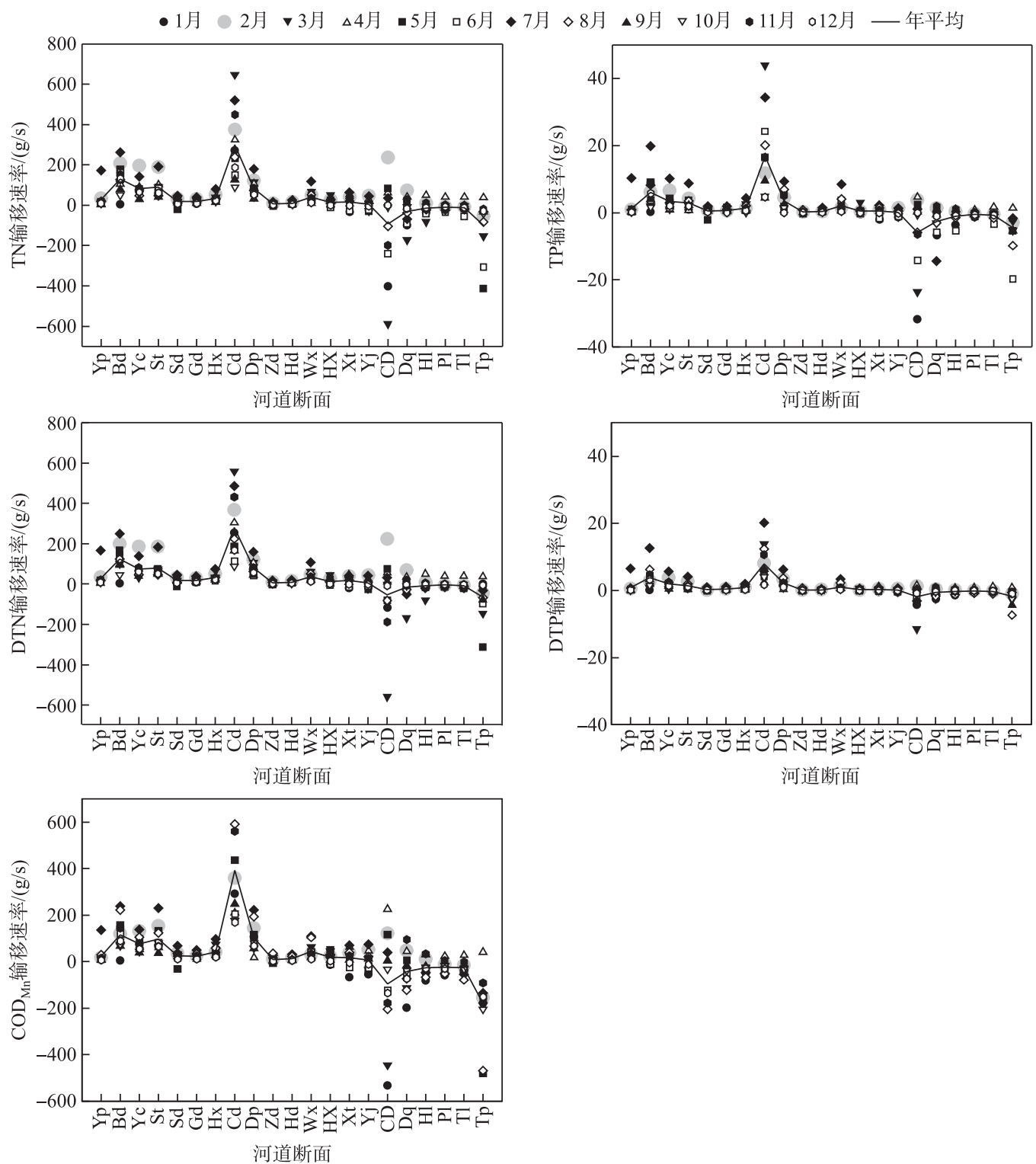

图 4 太湖西部环湖河道污染物输移速率

Fig.4 Pollutant transport rates of the 21 rivers around western Lake Taihu

统计主要河道污染物输移速率可以看出城东港是污染物的主要输人河道,各类物质输人速率占太湖西 部河道总输人速率的 $30 \%$ 以上, 其次是百渎港、大浦港和沙塘港 (表 1). 上述 4 条河道对 TN、DTN、TP、DTP 和 $\mathrm{COD}_{\mathrm{Mn}}$ 的输人速率分别为 $604.3 、 561.9 、 29.5 、 15.4$ 和 $708.8 \mathrm{~g} / \mathrm{s}$, 占西部河道总输人速率的 $62.7 \% 、 63.6 \%$ 、 $67.1 \% 、 66.6 \%$ 和 $64.8 \%$. TN 、DTN、TP、DTP、COD ${ }_{\mathrm{Mn}}$ 主要通过太浦河、长䚌港和大钱港输出太湖, 3 条河道上述 
指标的输出速率分别为 $221.2 、 135.9 、 12.8 、 4.2$ 和 $316.6 \mathrm{~g} / \mathrm{s}$, 占总输出速率的 $86.5 \% 、 86.9 \% 、 85.0 \% 、 85.3 \%$ 和 $80.6 \%$. 统计结果表明, 城东港、百渎港、大浦港和沙塘港是人湖污染物尤其是氮总量控制的重点治理目标, 其 TN 输人速率为 $604.3 \mathrm{~g} / \mathrm{s}$, 估算每天氮的输人量达 $52.2 \mathrm{t}$, 对太湖造成较高的外源污染负荷.

表 1 主要河道的污染物输移速率 $(\mathrm{g} / \mathrm{s})$ 及其在总输人/输出速率的占比

Tab.1 Percentage of pollutants transport rate and its average value of the main rivers

\begin{tabular}{|c|c|c|c|c|c|c|c|c|}
\hline \multirow{2}{*}{ 污染物 } & & \multicolumn{4}{|c|}{ 输人 } & \multicolumn{3}{|c|}{ 输出 } \\
\hline & & 城东港 & 百渎港 & 大浦港 & 沙塘港 & 太浦河 & 长䣨港 & 大钱港 \\
\hline \multirow[t]{2}{*}{$\mathrm{TN}$} & 输移速率 & 300.4 & 130.5 & 83.7 & 89.6 & 98.3 & 93.3 & 29.6 \\
\hline & 占比 & $31.20 \%$ & $13.50 \%$ & $8.70 \%$ & $9.30 \%$ & $38.40 \%$ & $36.50 \%$ & $11.60 \%$ \\
\hline \multirow[t]{2}{*}{ DTN } & 输移速率 & 278.5 & 124.2 & 80.5 & 78.6 & 65.6 & 53.7 & 16.6 \\
\hline & 占比 & $31.50 \%$ & $14.10 \%$ & $8.90 \%$ & $9.10 \%$ & $41.90 \%$ & $34.30 \%$ & $10.60 \%$ \\
\hline \multirow[t]{2}{*}{$\mathrm{TP}$} & 输移速率 & 16.9 & 6.1 & 3.6 & 2.9 & 4.4 & 5.9 & 2.6 \\
\hline & 占比 & $38.50 \%$ & $13.80 \%$ & $8.20 \%$ & $6.60 \%$ & $29.30 \%$ & $38.80 \%$ & $16.90 \%$ \\
\hline \multirow[t]{2}{*}{ DTP } & 输移速率 & 7.9 & 3.8 & 2.2 & 1.4 & 1.7 & 1.8 & 0.6 \\
\hline & 占比 & $34.40 \%$ & $16.30 \%$ & $9.60 \%$ & $6.30 \%$ & $35.60 \%$ & $36.70 \%$ & $13.10 \%$ \\
\hline \multirow[t]{2}{*}{$\mathrm{COD}_{\mathrm{Mn}}$} & 输移速率 & 392.6 & 116.1 & 103.4 & 96.7 & 179.8 & 95.4 & 41.4 \\
\hline & 占比 & $35.90 \%$ & $10.60 \%$ & $9.40 \%$ & $8.80 \%$ & $45.80 \%$ & $24.30 \%$ & $10.50 \%$ \\
\hline
\end{tabular}

统计分析不同水情条件下 5 种污染物的输人、输出速率 (表 2), 发现环湖河道 TN 汛前净输人速率较 大, 为 $748.9 \mathrm{~g} / \mathrm{s}$, 汛期和汛后人湖速率出现不同程度下降, 但净输人速率较为接近, 分别为 557.69 和 553.79 $\mathrm{g} / \mathrm{s}$. DTN 汛前净输人速率为 $773.3 \mathrm{~g} / \mathrm{s}$, 汛期和汛后逐步降低. 在不同水情条件下 DTN 的净输人速率高于 $\mathrm{TN}$, 表明太湖溶解性氮的输出能力较弱. TP 和 DTP 净输人速率均在汛期明显增大, 分别为 35.5 和 $24.0 \mathrm{~g} / \mathrm{s}$, 汛前和汛后净输人速率较为接近. $\mathrm{COD}_{\mathrm{Mn}}$ 净输人速率同样在汛期较高, 汛后最低. 表明 $\mathrm{TP} 、 \mathrm{DTP}$ 和 $\mathrm{COD}_{\mathrm{Mn}}$ 的 污染负荷受水情影响较大.

表 2 不同水情下太湖环湖河道污染物输人、输出和净输人速率 $(\mathrm{g} / \mathrm{s})$

Tab.2 The sum of pollutants transport rate of the rivers around Lake Taihu in different hydrological conditions

\begin{tabular}{|c|c|c|c|c|c|c|c|c|c|}
\hline \multirow{2}{*}{ 污染物 } & \multicolumn{3}{|c|}{ 汛前 } & \multicolumn{3}{|c|}{ 汛期 } & \multicolumn{3}{|c|}{ 汛后 } \\
\hline & 人湖 & 出湖 & 净输人 & 人湖 & 出湖 & 净输人 & 人湖 & 出湖 & 净输人 \\
\hline $\mathrm{TN}$ & 1034.3 & 285.4 & 748.9 & 878.0 & 320.4 & 557.6 & 662.2 & 108.5 & 553.7 \\
\hline DTN & 939.9 & 166.6 & 773.3 & 812.0 & 192.4 & 619.6 & 636.9 & 82.6 & 554.3 \\
\hline $\mathrm{TP}$ & 34.0 & 16.6 & 17.4 & 55.7 & 20.2 & 35.5 & 24.5 & 4.7 & 19.8 \\
\hline DTP & 16.3 & 5.3 & 11.0 & 29.6 & 5.6 & 24.0 & 15.7 & 3.4 & 12.3 \\
\hline $\mathrm{COD}_{\mathrm{Mn}}$ & 895.1 & 346.3 & 548.8 & 1242.6 & 482.7 & 759.9 & 763.5 & 305.8 & 457.7 \\
\hline
\end{tabular}

\section{3 讨论}

\section{1 输移速率与流量和污染物浓度关系}

各河道污染物浓度和流量相关性统计结果呈现出一定的差异. 除殷港和沙塘港 TN 浓度与流量呈正相 关, 其他所有人湖河道 TN 浓度均随流量增加有降低趋势, 尽管相关性并不显著, 但一定程度上表明陆域水 文过程对氮起到一定的稀释作用. 社渎港和城东港 TP 浓度与流量呈负相关, 其他所有人湖河道 TP 浓度均 随流量增加有升高趋势, 其中雅浦港、殷村港、沙塘港 TP 浓度与流量呈显著正相关, 表明降雨过程加剧了陆 域磷的污染负荷. 污染物的输移速率则主要受流量控制, $V_{\mathrm{TN}} 、 V_{\mathrm{DTN}} 、 V_{\mathrm{TP}} 、 V_{\mathrm{DTP}}$ 和 $V_{\mathrm{COD}_{\mathrm{N}}}$ 均与流量呈显著相关 $(P<0.01)$. 除了城东港, 其他各人湖河道的 $V_{\mathrm{TN}}$ 均与流量呈显著相关 $(P<0.05)$, 输人速率主要受来水量的影 响. 城东港 $V_{\mathrm{TN}}$ 与 $\mathrm{TN}$ 浓度呈显著相关 $(r=0.667, P<0.01)$, 除此之外沙塘港、殷村港、合溪新港 $V_{\mathrm{TN}}$ 除了与流 
量呈显著相关, 同样与 TN 浓度呈显著相关 $(P<0.01)$. 表明控制城东港、沙塘港、殷村港和合溪新港的 TN 浓 度对于降低人湖氮负荷具有关键影响. $V_{\mathrm{DTN}}$ 与 $V_{\mathrm{TN}}$ 规律一致 $(r=0.971, P<0.05)$. 城东港 $V_{\mathrm{TP}}$ 与 $\mathrm{TP}$ 浓度呈显 著相关 $(r=0.764, P<0.05)$, 与流量无相关性, 而其他人湖河道 $V_{\mathrm{TP}}$ 与 $\mathrm{TP}$ 浓度和流量均表现出显著相关性 $(P<0.05)$. 城东港 TP 浓度为人湖河道最高, 控制其 TP 浓度是外源磷污染治理的关键. 各人湖河道 $V_{\mathrm{COD}_{\mathrm{W}}}$ 与 流量均呈显著相关, 此外殷村港、沙塘港、洪巷港、城东港、大浦港 $V_{\mathrm{COD}_{\mathrm{wn}}}$ 还与 $\mathrm{COD}_{\mathrm{Mn}}$ 浓度呈显著相关 $(P<0.05)$.

\section{2 输移速率对湖体水质的影响}

为了探讨河口附近湖体水质对污染物浓度和输移速率的响应, 统计近岸湖体 (L1 点) TN 、 TP 和 $\mathrm{COD}_{\mathrm{Mn}}$ 浓度与社渎港、官渎港、洪巷港、城东港和大浦港的浓度, 发现湖体与各河道水质均无显著相关性 (图 5). 但 对 5 条河道的 $V_{\mathrm{TN}}$ 进行求和后与湖体浓度进行相关性分析, 发现除了 7 月强降雨导致人湖速率异常升高外, 其他月份变化趋势较为接近, 在去除 7 月的影响后, 二者显著相关 $(r=0.971, P<0.01)$. 表明湖体 TN 浓度虽 然不直接与河道浓度显著相关, 但非极端水情条件下湖体浓度与周边河道的综合输人速率呈显著相关. 因 此, 降低湖西区近岸水体 $\mathrm{TN}$ 浓度的关键是控制城东港的 $\mathrm{TN}$ 浓度, 这是由于城东港 $V_{\mathrm{TN}}$ 占人湖总 $V_{\mathrm{TN}}$ 的 $31.2 \%$, 且其 $V_{\mathrm{TN}}$ 受河道 $\mathrm{TN}$ 浓度控制. 人湖 $\mathrm{TP}$ 和 $\mathrm{COD}_{\mathrm{Mn}}$ 污染负荷较低, 统计结果表明 $V_{\mathrm{TP}}$ 和 $V_{\mathrm{COD}_{\mathrm{wn}}}$ 与湖体 $\mathrm{TP}$ 和 $\mathrm{COD}_{\mathrm{Mn}}$ 浓度并无显著相关性.
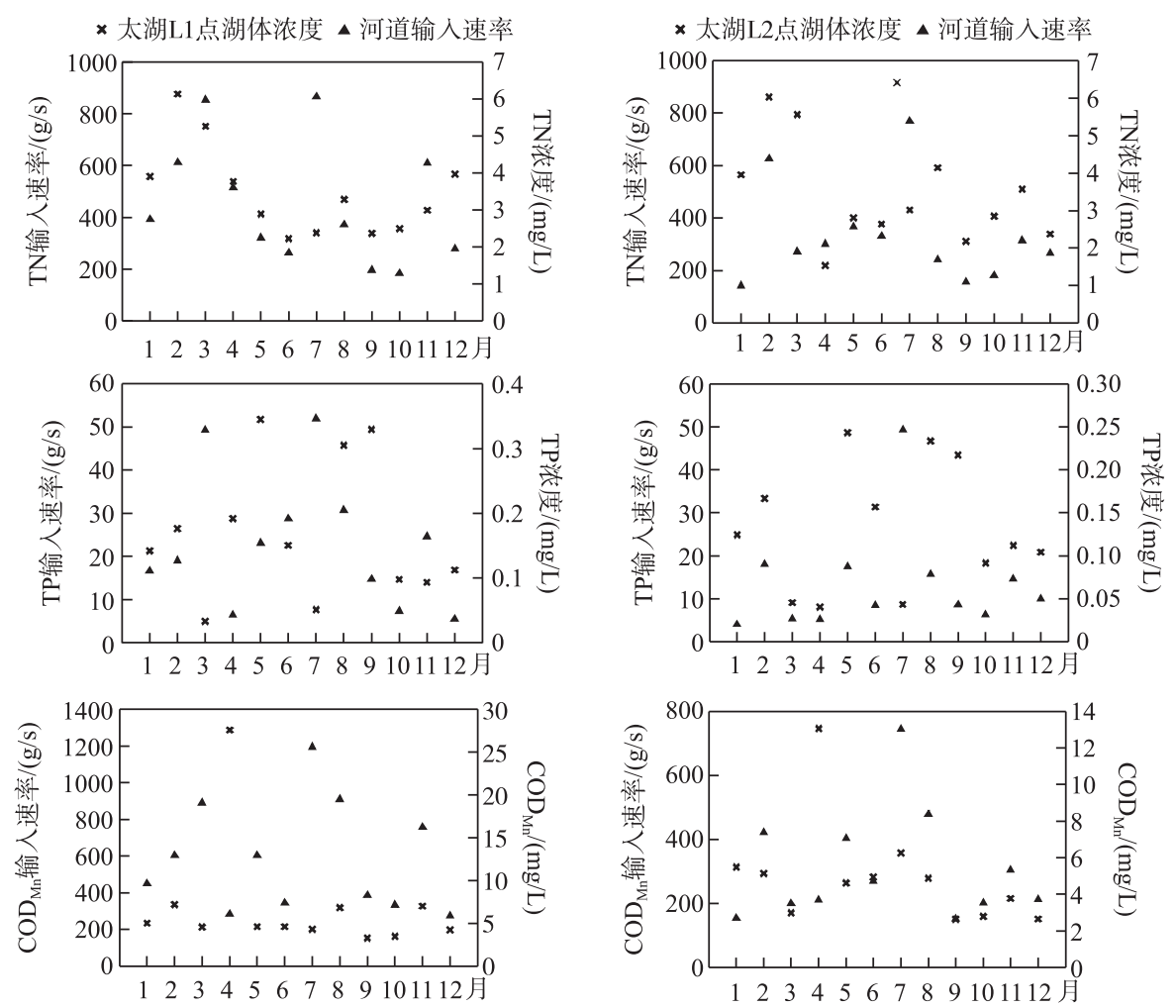

图 5 人湖河道污染物输移速率与湖体浓度同期对比

Fig.5 Correlations of pollutant input rate of the rivers around Lake Taihu and pollutant concentrations in the lake

统计竺山湾 ( $\mathrm{L} 2$ 点) $\mathrm{TN} 、 \mathrm{TP} 、 \mathrm{COD}_{\mathrm{Mn}}$ 浓度与雅浦港、百渎港、殷村港和沙塘港 4 条人湖河道的关系, 探讨 半封闭型湖湾浓度对河道的响应. 结果显示湖体浓度与河道浓度无显著相关性 (图 5), 与各河道 $V_{\mathrm{TN}} 、 V_{\mathrm{TP}}$ 和 $V_{\mathrm{COD}_{\mathrm{w}}}$ 以及 4 条河道输移速率之和同样不具显著相关性, 表明污染物人湖速率变化并不直接引起湖湾浓 度发生相应的改变. 其原因在于 L2 点位于湖湾中间位置, 与 L1 点相比距离河口较远, 湖体的稀释作用和自 
净功能使得 $\mathrm{TN} 、 \mathrm{TP}$ 和 $\mathrm{COD}_{\mathrm{Mn}}$ 浓度对人湖速率的响应不再明显. 现有研究结果表明太湖氮素年自净量约 $3.22 \times 10^{4} \mathrm{t}$, 占人湖氮素总量的 $46 \%^{[14]}$, 总磷自净量为 $1500 \mathrm{t}^{[15]}$, 竺山湾总氮、总磷年自净能力分别为 1979 和 $119 \mathrm{t}^{[16]}$. 目前 4 条河道综合 $V_{\mathrm{TN}} 、 V_{\mathrm{TP}}$ 和 $V_{\mathrm{COD}_{\mathrm{un}}}$ 分别为 $330.0 、 13.6$ 和 $313.0 \mathrm{~g} / \mathrm{s}$, 估算年人湖 $\mathrm{TN} 、 \mathrm{TP}$ 和 $\mathrm{COD}_{\mathrm{Mn}}$ 总量分别为 $10402 、 431$ 和 9870 t. 削减 4 条河道 $\mathrm{TP}$ 浓度以及沙塘港和殷村港 $\mathrm{TN} 、 \mathrm{COD}_{\mathrm{Mn}}$ 浓度是降低 竺山湾人湖污染负荷的关键. 此外, 竺山湾需要加强湖滨带的生态重建及湖体水生植被生态修复, 加强对人 湖污染物的拦截和植物吸收能力, 提升自净作用以应对当前较高的污染负荷.

\section{4 结论}

太湖西部人湖和出湖河道 TN 浓度变化存在显著性差异, 人湖 DTN/TN 比为 $91.1 \%$, 出湖降至 $77.5 \%$. 水情影响人湖水质, $\mathrm{TN}$ 浓度汛期降低 $31.5 \%$, 但 $\mathrm{TP}$ 和 $\mathrm{COD}_{\mathrm{Mn}}$ 浓度分别上升 $46.2 \%$ 和 $6.2 \%$, 汛后 $\mathrm{TN}$ 浓度回 升, TP 和 $\mathrm{COD}_{\mathrm{Mn}}$ 浓度下降.

环湖河道 TN、DTN、TP、DTP 和 $\mathrm{COD}_{\mathrm{Mn}}$ 净输人速率分别为 707.9、727.0、28.8、18.2 和 $700.9 \mathrm{~g} / \mathrm{s}$. 污染物的

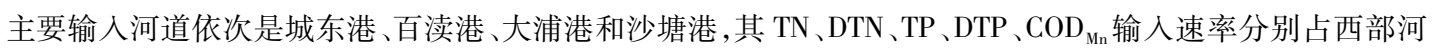
道总输人速率的 $62.7 \% 、 63.6 \% 、 67.1 \% 、 66.6 \%$ 和 $64.8 \%$. 太浦河、长覍港和大钱港上述指标输出速率分别占 总输出速率的 $86.5 \% 、 86.9 \% 、 85.0 \% 、 85.3 \%$ 和 $80.6 \%$.

污染物人湖速率在不同水情下具有显著性差异, TN 和 DTN 净输人速率汛前最大, 汛期和汛后下降 $25 \%$ 以上, TP、DTP 和 $\mathrm{COD}_{\mathrm{Mn}}$ 净输人速率汛期增大, 汛后分别降低 $44.2 \% 、 48.8 \%$ 和 $39.8 \%$. 城东港氮、磷输人速率 受浓度控制, 其他河道各指标输移速率受流量控制. 近岸湖体 TN 浓度与人湖速率呈显著正相关, 离岸湖体 $\mathrm{TN} 、 \mathrm{TP}$ 和 $\mathrm{COD}_{\mathrm{Mn}}$ 浓度对人湖速率的变化响应不明显.

\section{5 参考文献}

[ 1 ] Xu PZ, Qin BQ. Water quality and pollutant fluxes of surrounding rivers of Lake Taihu during the hydrological year of 2001-2002. J Lake Sci , 2005, 17(3) : 213-218. DOI: 10.18307/2005.0304. [许朋柱, 秦伯强. 2001-2002 水文年环 太湖河道的水量及污染物通量. 湖泊科学, 2005, 17(3) : 213-218.]

[ 2 ] Zhai SH, Zhang HJ. Water quality and waste load variation of rivers around Lake Taihu from 2000 to 2002. J Lake Sci, 2006, 18 (3) : 225-230. DOI: 10.18307/2006.0305. [翟淑华, 张红举. 环太湖河流进出湖水量及污染负荷 (20002002 年). 湖泊科学, $2006, \mathbf{1 8}(3): 225-230$. ]

[ 3 ] Yan SW, Yu H, Zhang LL et al. Water quantity and pollutant fluxes of inflow and outflow rivers of Lake Taihu, 2009. J Lake Sci, 2011, 23(6): 855-862. DOI: 10.18307/2011.0605. [燕姝雯, 余辉, 张璐璐等. 2009 年环太湖人出湖河流 水量及污染负荷通量. 湖泊科学, $2011,23(6): 855-862$. ]

[ 4 ] Yi J, Xu F, Gao Y et al. Variations of water quality of the major 22 inflow rivers since 2007 and impacts on Lake Taihu. $J$ Lake Sci, 2016, 28(6) : 1167-1174. DOI:10.18307/2016.0602. [易娟, 徐枫, 高怡等. 2007 年以来环太湖 22 条主 要河流水质变化及其对太湖的影响. 湖泊科学, 2016, 28(6): 1167-1174.]

[ 5 ] He XJ, Wang B, Liu GY et al. Water quality, quantity and pollutant fluxes variations of the rivers surrounding Lake Taihu in Zhejiang Province during hydrological year of 2010-2011. J Lake Sci, 2012, 24(5) : 658-662. DOI: 10.18307/2012. 0502. [何锡君, 王贝, 刘光裕等. 2010-2011 水文年浙江省环太湖河道水质水量及污染物通量. 湖泊科学, 2012, 24(5): 658-662.]

[ 6 ] Zha HM, Zhu MY, Zhu GW et al. Seasonal difference of water quality between lake and inflow/outflow rivers of Lake Taihu, China. Environmental Science, 2018, (3) : 1102-1112. [查慧铭, 朱梦圆, 朱广伟等. 太湖出入湖河道与湖体 水质季节差异分析. 环境科学, 2018, (3): 1102-1112.]

[ 7 ] Wang Q, Wu YD, Ding QL et al. Temporo-spatial variations and influential factors of water quality in the flowing river systems of western Taihu Lake Basin. China Environmental Science, 2017, 37(7) : 2699-2707. [王倩, 吴亚东, 丁庆玲等. 西太湖人湖河流水系污染时空分异特征及解析. 中国环境科学, 2017, 37(7): 2699-2707.]

[ 8 ] Lv XY, Zhang Y, Xu L et al. Nitrogen pollutants variation of typical rivers entering into Taihu Lake in summer-autumn period. Hydro-Science and Engineering, 2016, (5): 9-15. [吕学研, 张咏, 徐亮等. 典型人太湖河流夏-秋季氮素污染 变化特征. 水利水运工程学报, 2016, (5): 9-15.] 
[ 9 ] Wu QL, Ruan XH, Wu CM et al. Analyses of sources and transformation of nitrogen as a contaminant in the river and lake water in the western region of the Taihu Lake basin. Acta Scientiae Circumstantiae, 2015, 35(12): 3883-3889. [ 吴庆乐, 阮晓红, 吴朝明等. 太湖西部河湖氮污染物来源及转化途径分析. 环境科学学报, 2015, 35(12): 3883-3889.]

[10] Gao YX, Song YZ, Yu JH et al. Spatial and temporal distribution characteristics of different forms of phosphorus in three sorts of rivers around Lake Taihu. Environmental Science, 2016, 37(4): 1404-1412. [高永霞, 宋玉芝, 于江华等. 环 太湖不同性质河流水体磷的时空分布特征. 环境科学, 2016, 37(4) : 1404-1412.]

[11] Li L, Wang SR, Wang HF et al. Temporal and spatial variations of phosphorus loading and the forms, compositions and contributions in inlet river of Lake Dianchi. J Lake Sci, 2016, 28(5): 951-960. DOI:10.18307/2016.0504. [李乐, 王 圣瑞, 王海芳等. 滇池人湖河流磷负荷时空变化及形态组成贡献. 湖泊科学, 2016, 28(5): 951-960.]

[12] Tang XX, Jiang CY, Wang C et al. Responses of total phosphorus concentration to total phosphorus loading of inflow rivers in the western part of Chaohu Lake. Environmental Science \& Technology, 2017, 40(S1) : 176-180. [唐晓先, 蒋晨韵, 王璨等. 巢湖西半湖总磷浓度对人湖总磷负荷的响应. 环境科学与技术, 2017, 40(S1) : 176-180.]

[13] Jin XC, Tu QY eds. The standard methods in lake eutrophication investigation: second edition. Beijing: China Environmental Science Press, 1990. [金相灿, 屠清瑛. 湖泊富营养化调查规范: 第二版. 北京: 中国环境科学出版 社, 1990.]

[14] Chen XF, Chuai XM, Zeng J. Nitrogenous fluxes and its self-purification capacity in Lake Taihu. Environmental Science, $2012,33(7)$ : 2309-2314. [陈小锋, 揣小明, 曾巾等. 太湖氮素出人湖通量与自净能力研究. 环境科学, 2012,33 (7) : 2309-2314.]

[15] Zhai SH, Han T, Chen F et al. Self-purification capacity of nitrogen and phosphorus of Lake Taihu on the basis of mass balance. J Lake Sci, 2014, 26(2) : 185-190. DOI:10.18307/2014.0203. [翟淑华, 韩涛, 陈方等. 基于质量平衡的太 湖氮、磷自净能力计算. 湖泊科学, 2014, 26(2) : 185-190.]

[16] Han T, Zhai SH, Hu WP et al. Experiment and model simulation of self-purification capacity of nitrogen and phosphorus in Lake Taihu. Environmental Science, 2013, 34(10) : 3862-3871. [韩涛, 翟淑华, 胡维平等. 太湖氮、磷自净能力的实 验与模型模拟. 环境科学, $2013, \mathbf{3 4}(10): 3862-3871$. 